bioRxiv preprint doi: https://doi org/10.1101/2020.02 08 940155; this version posted February 10, 2020. The copyright holder for this

preprint (which was not certified by peer review) is the author/funder, who has granted bioRxiv a license to display the preprint in perpetuity. It is made available under aCC-BY-NC-ND 4.0 International license.

\title{
Modelling thalamocortical circuitry shows visually induced LTP changes laminar connectivity in human visual cortex
}

\author{
Rachael L. Sumner ${ }^{*}$, Meg J. Spriggs² ${ }^{2}$ Alexander D. Shaw ${ }^{3}$ \\ ${ }^{1}$ School of Pharmacy, University of Auckland, New Zealand, ${ }^{2}$ Centre for Psychedelic Research, Department of \\ Medicine, Imperial College London, UK, ${ }^{3}$ Cardiff University Brain Research Imaging Centre (CUBRIC), Cardiff \\ University, CF24 4HQ, UK.
}

\section{*Corresponding Author:}

Rachael L. Sumner,

School of Pharmacy, University of Auckland.

Private Bag 92019, Auckland 1142, New Zealand.

rsum009@aucklanduni.ac.nz 
bioRxiv preprint doi: https://doi org/10.1101/2020.02 08 940155; this version posted February 10, 2020. The copyright holder for this preprint (which was not certified by peer review) is the author/funder, who has granted bioRxiv a license to display the preprint in perpetuity. It is made available under aCC-BY-NC-ND 4.0 International license.

\begin{abstract}
Neuroplasticity is essential to learning and memory in the brain; it has therefore also been implicated in numerous neurological and psychiatric disorders, making measuring the state of neuroplasticity of foremost importance to clinical neuroscience. Long-term potentiation (LTP) is a key mechanism of neuroplasticity and has been studied extensively, and invasively in non-human animals. Translation to human application largely relies on the validation of non-invasive measures of LTP. The current study provides validation for the use of a thalamocortical computational model of visual cortex for investigating and replicating interlaminar connectivity changes using non-invasive EEG recording of humans, and a commonly used visual sensory LTP paradigm. The model demonstrated remarkable accuracy recapitulating post-tetanus changes including increased excitatory connectivity from thalamus to layer IV and from layer IV to II/III. The findings also further validate visual sensory induced LTP and evoked potential modulation for measuring of the state of LTP in cortex.
\end{abstract}


bioRxiv preprint doi: https://doi.org/10.1101/2020.02.08.940155; this version posted February 10, 2020. The copyright holder for this preprint (which was not certified by peer review) is the author/funder, who has granted bioRxiv a license to display the preprint in perpetuity. It is made available under aCC-BY-NC-ND 4.0 International license.

\section{Introduction}

Experience dependent learning in the brain can be studied via the induction and recording of longterm potentiation (LTP). LTP is an enduring change in synaptic efficacy following repeated input of a stimulus and is therefore thought to underlie learning and memory in the brain (Bliss \& Collingridge, 1993; Bliss \& Lømo, 1973). The complementary mechanism of long-term depression (LTD) reduces synaptic efficacy but is considered just as important as LTP for healthy learning and memory. LTP and LTD are prolific both in hippocampus and in cortex and as a result their dysfunction has been implicated in a number of neurological and psychiatric disorders (Cooke \& Bear, 2010). The importance of LTP has led to considerable efforts to develop a non-invasive measure to assess the state of synaptic LTP in humans, in particular for research into clinical populations. One of the most commonly used measures uses high-frequency visual stimulation to induce a lasting change in the visually evoked potential, a validated product of LTP in the visual cortex (Sumner, Spriggs, Muthukumaraswamy, \& Kirk, Under Review).

The most commonly studied form of LTP in hippocampus and in cortex is N-methyl-D-aspartate receptor (NMDAR) dependent LTP. Of interest to the current paper, the plasticity of visual cortex in adult rodents has been tested extensively. Electrical theta-burst stimulation (TBS) in dorsal lateral geniculate nucleus (dLGN) and direct to cortex induces NMDAR dependent LTP within the laminar connections of primary visual cortex. Such research has determined that layers II, III and IV are key sites of synaptic modification following TBS (Heynen \& Bear, 2001; Kirkwood \& Bear, 1994). Theoretically, this direct electrical stimulation induced LTP, is similar to the naturalistic transmission along thalamocortical pathways that would be expected to occur with visual stimulation. Therefore the product of this transmission increase ought to be detectable in response to visual input. Heynen and Bear (2001) showed this in rodents using pattern reversal sine grating stimulation, where 60 minutes post stimulation the visually evoked potential (VEP) was approximately $134 \%$ of baseline. This finding was later corroborated by Cooke and Bear (2010). After five days of exposure of sine grating stimuli the VEP recorded from layer IV of rodents was enhanced. The VEP modification was NMDAR dependent, and also specific to the spatial frequency of the training sine-grating.

Translation of findings from rodent research to human research requires that associative plasticity in cortex is governed by similar rules, despite some variation in mechanisms. This has been demonstrated in adult primate visual cortex (rhesus macaque) (Huang et al., 2014). Field potentials recorded in layer III following stimulation in layer IV demonstrated both LTP (using TBS) and LTD (using $1 \mathrm{~Hz}$ stimulation), providing support for the use of visual cortex as an accessible site for assaying the state of LTP/LTD using non-invasive techniques (Huang et al., 2014).

In humans the visual LTP paradigm typically utilises high-frequency $(\sim 9 \mathrm{~Hz})$ visual stimulation to induce change in the VEP (Sumner et al., Under Review; Teyler et al., 2005). First there is a baseline recording of the VEP using $\sim 1 \mathrm{~Hz}$ presentations of a stimulus. Following a $\sim 9 \mathrm{~Hz}$ photic tetanus, a post-tetanus recording determines if LTP has been induced within minutes and then if it has been sustained longterm (typically 30-40 minutes post-tetanus). The change is commonly associated with LTP when localized to enhancement of the N1 and P2 early VEP components (Sumner et al., Under Review). It has been proposed that the $9 \mathrm{~Hz}$ stimulation determines the interburst frequency of neural circuitry, similar to electrical tetanic bursts (Clapp, Hamm, Kirk, \& Teyler, 2012; Kirk et al., 2010). Additionally, the paradigm has demonstrated key Hebbian characteristics including specificity of potentiation to the spatial frequency and orientation of sine grating stimuli (McNair et al., 2006; Ross et al., 2008; Sumner et al., 2020). When used in rodents, the induced LTP is NMDAR specific (Clapp, Eckert, Teyler, \& Abraham, 2006), and in humans is enhanced by D-cycloserine (a partial agonist at the glycine site of NMDARs) (Forsyth, Bachman, Mathalon, Roach, \& Asarnow, 2015). 
bioRxiv preprint doi: https://doi.org/10.1101/2020.02.08.940155; this version posted February 10, 2020. The copyright holder for this preprint (which was not certified by peer review) is the author/funder, who has granted bioRxiv a license to display the preprint in perpetuity. It is made available under aCC-BY-NC-ND 4.0 International license.

The obvious advantage of the visual LTP paradigm is the non-invasive nature of EEG and visual stimulation. This allows for not only widespread use of the method in humans, but also for the assessment of LTP uninfluenced by anaesthetic agents, which is rare in rodent studies using visual stimulation and is thought to have caused issue with replication in the past (Eckert, Guevremont, Williams, \& Abraham, 2013). However, in using EEG and the visual LTP paradigm, the rich profile of cortical changes that occur as a result of LTP induction such as those reported in animal invasive studies (Cooke \& Bear, 2010; Heynen \& Bear, 2001; Huang et al., 2014) are largely lost. Evoked potential changes merely allow for the distinction of relatively increased and relatively decreased LTP or LTD in different groups or conditions in a study.

Computational modelling techniques such as dynamic causal modelling (DCM) and the neural-mass or mean field models typically employed, provide the mathematical means to estimate the pooled response of a large population of neurons (Moran, Pinotsis, \& Friston, 2013). Pertinent to the generation of VEPs, the EEG signal is estimated to include the pooled response of 10,000 to 50,000 neurons (Murakami \& Okada, 2006). The VEP recorded from the surface of both rodents and humans is known to reflect primarily the superficial layers and the apical projections of pyramidal neurons. However, this response is the product of a hierarchical and reciprocal connectivity structure of excitatory and inhibitory inputs influencing the action of, and acting upon, superficial (II/III) layers; as well as a smaller contribution of the deeper layers (Bastos et al., 2012; Douglas \& Martin, 1991; Douglas, Martin, \& Whitteridge, 1989; Murakami \& Okada, 2006). This was first described by Douglas et al. (1989) as the canonical microcircuit of cat neocortex. A hierarchical organization of connectivity is described by Felleman and Van Essen (1991). Thus, providing the basis for the development of biologically plausible computational models of the canonical microcircuit that estimate the neural causes of EEG signal.

To better exploit the detail of EEG recordings of VEP enhancement, recent studies in humans have employed computational modelling in network-based analyses of the excitatory cortico-cortical connections involved in visual processing. Connectivity changes associated with the visual LTP paradigm have been assessed using DCM and an adapted, simple Jansen and Rit (1995) neural mass model for evoked-potential research. To construct these networks, the sources typically associated with the induced LTP related change include greater activation in the extrastriate visual cortex, dorsal and ventral visual streams, and frontal cortex (Spriggs et al., 2018; Sumner et al., 2020; Sumner, Spriggs, et al., 2018b). As a result of Hebbian plasticity changes, modulation of excitatory forward projecting connections, as well as local modulation of the cortical microcircuit has been replicated (Spriggs et al., 2018; Sumner et al., 2020; Sumner, Spriggs, et al., 2018b). However, there is a lack of rodent research on the impact of LTP on cortico-cortical network connectivity to allow for detailed inference on the nature of resulting changes. One way to overcome this would be to model visual cortex more similarly to how it is studied invasively in animals and to assess the reciprocal laminar connectivity changes leading to LTP triggered VEP modulation. This requires moving beyond the three population, simple Jansen and Rit (1995) neural mass model that lacks laminar resolution.

Recently, computational models have expanded to include increasingly detailed recapitulations of the canonical microcircuit and local laminar connectivity. Moreover, conductance models for both spectral and evoked response data capture non-linear as well as linear dynamics intrinsic to a wider range of cell populations and ion channel properties (Moran et al., 2013). Particularly pertinent to data containing sensory perturbation, Shaw et al. (2019) present a model that incorporates realistic thalamic parameters that capture relay projections into layers IV and VI including intrinsic inhibitory and excitatory connections. 
bioRxiv preprint doi: https://doi.org/10.1101/2020.02.08.940155; this version posted February 10, 2020. The copyright holder for this preprint (which was not certified by peer review) is the author/funder, who has granted bioRxiv a license to display the preprint in perpetuity. It is made available under aCC-BY-NC-ND 4.0 International license.

The model was employed in the current study with the aim of capturing the induction of LTP in visual cortex following $\sim 9 \mathrm{~Hz}$ visual stimulation in the classical visual LTP paradigm (Sumner et al., Under Review). It was hypothesised that the changes seen in Heynen and Bear (2001) and Huang et al. (2014) would be replicated. This includes an increase in excitatory connectivity projecting from thalamus into layer IV, and from layer IV into layer III. While less well documented the model will allow for the inhibitory changes to occur, potentially as a result LTP occurring on inhibitory interneurons. LTP on GABAergic interneurons has been found in hippocampus and cortex (Kullmann \& Lamsa, 2011), including following TBS to visual cortex (Sarihi et al., 2008). LTP on GABAergic interneurons related to visually induced LTP may or may not be NMDA dependent and such findings will be exploratory.

NDMAR dependent LTP has multiple phases which will be explored using Bayesian Model Selection (BMS) and can be termed short-term potentiation (STP), early phase LTP (E-LTP), and late phase LTP (L-LTP). These phases are dependent on different molecular processes or stages (Bliss \& Collingridge, 1993; Teyler \& DiScenna, 1987). STP is considered relatively unstable, and persists for 15-30 minutes (Malenka, 1991). Therefore, it has been suggested that early potentiation of the VEP (a couple of minutes post-tetanus), that is slightly decayed by the late post-tetanus block (commonly the N1 (Sumner et al., Under Review)), is likely contaminated by STP. Where potentiation 30 minutes posttetanus onward is likely to predominantly reflect E-LTP, and may contain some products of the conversion to L-LTP (Sumner et al., 2020; Sumner et al., Under Review). BMS will allow for an investigation of the different time courses of potentiation in VEPs, and how these might be reflective of the interaction of STP as well as E-LTP mechanisms. The modelling is accompanied by ERP analyses to confirm the photic tetanus induced significant modulation of the VEP.

\section{Methods}

\section{$\underline{\text { Participants }}$}

Twenty young adults (sex: 9 males, 11 females), age range: $21-32$ (mean $=24.35$ ) took part in the visual LTP paradigm. The data from all females has been previously reported in Sumner, Spriggs, et al. (2018b). All datasets from females were collected during the follicular phase (day 3-5) of the menstrual cycle when progesterone and oestradiol levels are low in order to control for hormonal effects on LTP (Smith \& McMahon, 2005; Sumner, Spriggs, et al., 2018b; Warren, Humphreys, Juraska, \& Greenough, 1995). Participants had no history of neurological or psychiatric disorder and were not taking any psychoactive medications. They had normal or corrected to normal vision. The study was approved by the University of Auckland Human Ethics Committee. Participants provided informed written consent prior to participation.

\section{EEG acquisition}

Continuous EEG was recorded using 64 channel Acticap $\mathrm{Ag} / \mathrm{AgCl}$ active shielded electrodes and Brain Products MRPlus amplifiers. Data were recorded in Brain Vision Recorder (Brain Products GmbH, Germany) with a $1000 \mathrm{~Hz}$ sampling rate and $0.1 \mu \mathrm{V}$ resolution. $\mathrm{FCz}$ was used as an online reference and $A F z$ as ground. Electrode impedance below $10 \mathrm{k} \Omega$ was achieved prior to recording. Stimuli were displayed on an ASUS VG248QE computer monitor with a screen resolution of $1920 \times 1080$ and 144 $\mathrm{Hz}$ refresh rate. TTL pulses generated through the parallel port of the display computer provided synchronization of stimulus events with EEG acquisition. All stimuli were generated by 
bioRxiv preprint doi: https://doi.org/10.1101/2020.02.08.940155; this version posted February 10, 2020. The copyright holder for this preprint (which was not certified by peer review) is the author/funder, who has granted bioRxiv a license to display the preprint in perpetuity. It is made available under aCC-BY-NC-ND 4.0 International license.

MATLAB (The MathWorks, Inc., Natick, MA) using the Psychophysics Toolbox (Brainard, 1997; Kleiner et al., 2007; Pelli, 1997).

\section{$\underline{\text { Visual LTP paradigm }}$}

Visual LTP was measured using an established paradigm that induces enhancements in the early VEP component as a product of LTP occurring in the visual cortex (Sumner et al., Under Review). The task stimuli were horizontal and vertical sine gratings, with a spatial frequency of 1 cycle per degree. They were presented at full contrast on a grey background, and subtended 8 degrees of visual angle. Participants were seated with their eyes $90 \mathrm{~cm}$ from the centre of the screen and were instructed to passively fixate on a centrally presented red dot.

The paradigm comprised four conditions (Figure 1). In the first, pre-tetanus condition, both stimuli were presented in a random order 240 times at $1 \mathrm{~Hz}$ for $34.8 \mathrm{~ms}$ and takes approximately 8 minutes. The interstimulus interval was varied using 5 intervals from 897-1036 ms that occurred randomly but equally often. The purpose of the pre-tetanus condition was to establish a baseline ERP amplitude for subsequent comparison with post-tetanus conditions. The second condition was a 2 minute photic tetanus or high-frequency stimulation involving 1000 presentations of either the horizontal or vertical stimulus which can be used to test input-specificity (McNair et al., 2006; Ross et al., 2008) (counterbalanced between participants) for $34.8 \mathrm{~ms}$ with a temporal frequency of approximately 9 $\mathrm{Hz}$. The $9 \mathrm{~Hz}$ frequency was chosen as it has been shown to reliably induce potentiation of the VEP (Clapp et al., 2006; McNair et al., 2006; Ross et al., 2008; Spriggs, Cadwallader, Hamm, Tippett, \& Kirk, 2017; Teyler et al., 2005) but is below the rate of perceptual fusion (Skrandies, 1985). The interstimulus interval was either 62.6 or $90.4 \mathrm{~ms}$ occurring at random but equally often. The third condition, referred to as the early post-tetanus condition, followed a 2-minute break, allowing retinal after images from the photic tetanus to dissipate and to ensure any effects measured were not just attributable to general cortical excitability. The fourth condition, referred to as the late post-tetanus block, followed 35-40 minutes after the early photic tetanus. For both post-tetanus conditions, horizontal and vertical stimuli are presented under the same conditions as the pre-tetanus, but with only 120 presentations of each lasting 4 minutes.

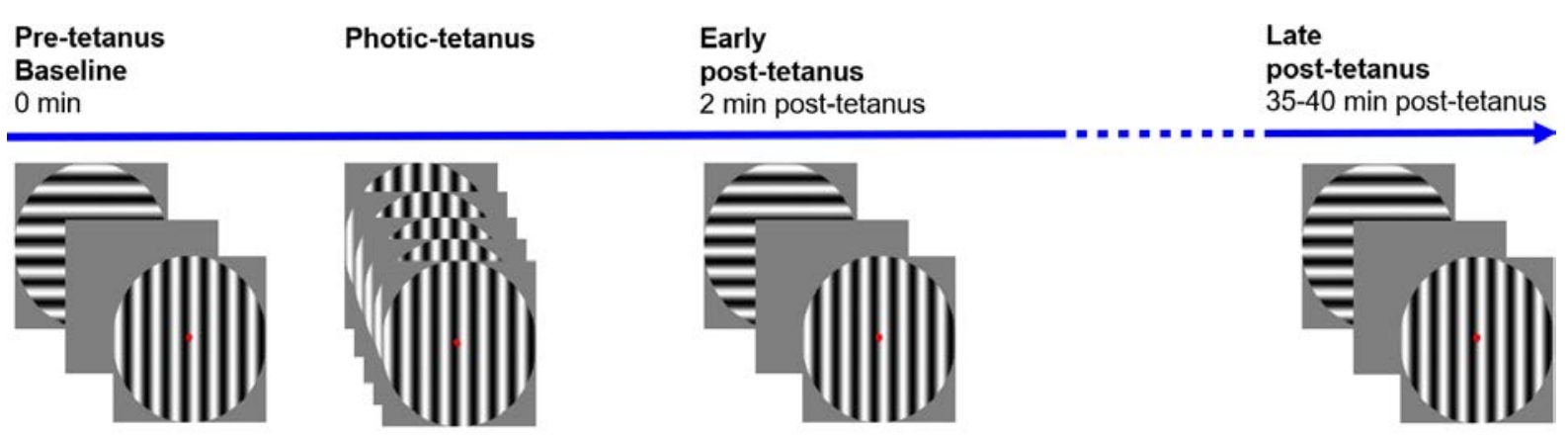

Figure 1. Schematic of the visual LTP paradigm. Adapted from Sumner et al. (2020).

\section{ERP: Pre-processing}

Pre-processing and data analyses were completed using the SPM12 toolbox (http://www.fil.ion.ucl.ac.uk/spm/software/spm12/). Data were re-referenced to the common average. A 0.1-30 Hz Butterworth bandpass filter removed slow drifts and high frequency noise. The 
bioRxiv preprint doi: https://doi.org/10.1101/2020.02.08.940155; this version posted February 10, 2020. The copyright holder for this preprint (which was not certified by peer review) is the author/funder, who has granted bioRxiv a license to display the preprint in perpetuity. It is made available under aCC-BY-NC-ND 4.0 International license.

LTP data were epoched into $700 \mathrm{~ms}$ sections $(-100 \mathrm{~ms}$ to $500 \mathrm{~ms}$ ) and then baselined. Eye blinks were removed using a $100 \mathrm{uV}$ threshold applied to electrodes Fp1, and Fp2 (or AF7, and AF8 if Fp1, and Fp2 electrodes were bad). As the sensory LTP task relies on visual input, and a $100 \mathrm{uV}$ threshold can miss small blinks and saccades along with other muscular and electrical artefacts, manual artefact rejection was also carried out. The manual artefact rejection first consisted of semi-automated trial rejection using the data summary tool from the SPM12 integrated FieldTrip visual artefact rejection toolbox (ft_rejectvisual). Each trial was then visually inspected using the SPM12 integrated FieldTrip data browser ( $\mathrm{ft}$ _databrowser) to remove any trials containing artefacts that did not meet the threshold of the previous steps. Finally, ICA was carried out to remove any residual artefact. Components representing ocular/electrocardiogram artifacts were identified based on their topography and time course and removed for each participant (typically 1 component).

\section{ERP: Analysis}

The pre-processed data were averaged by condition. The trial averages were converted to NIfTI images using a time-window of 0-250 ms, and images were smoothed using a 6×6×6 FWHM Gaussian kernel. ERP analyses in SPM12 represent space by time data as a continuous statistical parametric map, and employs random field theory to control family-wise error rate. This approach allows for the analysis of large temporal and spatial regions of interest, in the current study this included the entire $0-250 \mathrm{~ms}$ time-window and all electrodes, while also controlling for the multiple comparisons problem (Kilner \& Friston, 2010).

The purpose of the ERP analysis was to confirm modulation of the ERP had occurred and so was conducted solely to demonstrate evidence of VEP modulation post-tetanus. As in previous studies an occipito-parietal ROI was employed, comprising the following electrodes: P1, P2, P3, P4, P5, P6, P7, P8, Pz, PO3, PO4, PO7, PO8, PO9, PO10, POz, O1, O2, and Oz (Spriggs et al., 2018; Sumner, McMilllan, et al., 2018). A 3-way repeated measures ANOVA was implemented across a $250 \mathrm{~ms}$ time window. For this analysis the contrasts of interest were an effect of the high frequency stimulation on both the early post-tetanus and late post-tetanus blocks. Only the stimulus used in the photic tetanus for individual participants (horizontal or vertical sine gratings depending on allocation) were used in the current study for simplicity. Simple effects analyses were carried out as appropriate. Results were interpreted at the peak level, and effects were considered significant at $p<0.05$ family-wise error corrected (FWE-c).

\section{$\underline{\text { Source analysis }}$}

Sources analysis was carried out using Multiple Sparse Priors, as implemented in SPM12, for group inverse reconstruction (Litvak \& Friston, 2008).

\section{Computational model of microcircuitry}

This study implemented a thalamocortical model of interlaminar connectivity (Figure 2). The model builds upon and extends the cortical 'cmm_NDMA' model implemented in DCM (Moran et al., 2015; Moran, Symmonds, Stephan, Friston, \& Dolan, 2011; Muthukumaraswamy et al., 2015), employing Morris-Lecar conductance equations (Morris \& Lecar, 1981), scaled up to the mean field using the Fokker-Planck formalism (Moran et al., 2013).

The 'cmm_NMDA' model features 4 interconnected populations comprising layer IV spiny stellates, superficial (layer II/III) and deep (layer V) pyramidal populations, and a single pool on inhibitory 
interneurons. The thalamocortical model presented here extends this architecture to include an additional set of cortical inhibitory interneurons (allowing separate superficial and deep populations). Furthermore, we include an additional population of cortico-thalamic (aka thalamic projection) pyramidal neurons in layer VI (Adams et al., 2020). For the thalamus, we model one population of (excitatory) relay cells and one population of (inhibitory) reticular cells.

All populations are governed by conductance equations of the form:

$$
\begin{gathered}
C \frac{d V}{d t}=\sum g_{n}\left(V-V_{n}\right)+u \\
\dot{g}_{n}=\kappa_{n}\left(\varsigma_{n}-g_{n}\right) \\
\varsigma_{n}=\gamma_{i, j} \sigma\left(\mu_{v}^{j}-V_{R}, \sum j\right) \\
n=\left\{A M P A, N M D A, G A B A_{A}, G A B A_{B}, m, h\right\}
\end{gathered}
$$

Here, the mean membrane potential $(\mathrm{dV} / \mathrm{dt}$ ) of a population is represented by the sum of the different channels' $(n)$ conductance terms $(g)$, multiplied by their respective reversal potential $\left(V_{n}\right)$, plus any exogenous / endogenous input $(u)$.

The rate of change of conductance of channel $n$, denoted $g_{n}$, is calculated from the rate constant of the channel $\left(K_{n}\right)$ multiplied by the change in conductance, e.g. $\kappa_{n}\left(\varsigma_{n}-g_{n}\right)$. The conductance, $\varsigma_{n}$, is calculated from the third term in equation 1 , where the coupling parameter, $y_{i j}$, coupling population $j$ to $i$, is multiplied by the expected firing of source population $j$. The sigmoid function sigma represents the cumulative distribution function of the presynaptic depolarisation around a threshold potential of $V_{R}=-40 \mathrm{mV}$, which determines the proportion of cells firing.

Conductances were computed for 6 channel types; AMPA, NMDA, GABA $A$, GABA,$m$-currents and $h$ currents. $\mathrm{M}$ - and $\mathrm{h}$ - channels were only present on cortico-thalamic projection pyramids (layer 6 ) and on thalamic relay cells.

The full connectivity profile of the model is depicted in Figure 2A. Excitatory connections (black in Figure $2 \mathrm{~A}$ ) are modelled by AMPA and NMDA conductances whereas inhibitory connections (red in Figure $2 A$ ) are modelled by $G A B A_{A}$ and $G A B A_{B}$ conductances. As per previous formulations (Moran et al., 2011), NMDA channels are subject to voltage gating to represent magnesium block, represented by a sigmoid activation function:

$$
f_{M G}(V)=\frac{1}{1+0.2 \exp \left(-\alpha_{N M D A} V\right)}
$$

Such that the conductance-based equation for layers where NMDA is an included population becomes:

$$
\left.C \frac{d V}{d t}=\sum g_{n}\left(V_{n}-V\right)+\left(g_{N M D A} * f_{M G}(V) * V_{N M D A}-V\right)\right)+u
$$


bioRxiv preprint doi: https://doi.org/10.1101/2020.02.08.940155; this version posted February 10,2020 . The copyright holder for this preprint (which was not certified by peer review) is the author/funder, who has granted bioRxiv a license to display the preprint in perpetuity. It is made available under aCC-BY-NC-ND 4.0 International license.

The rate constants and reversal potentials of each channel are represented in Figure $2 \mathrm{C}$. Thalamocortical projections were subject to propagation delays of $3 \mathrm{~ms}$ and cortico-thalamic of $8 \mathrm{~ms}$ (Lumer, Edelman, \& Tononi, 1997).

For this analysis we constrained the parameters that were allowed to vary (during model fitting) according to the Douglas and Martin (2004) canonical microcircuit, and included all of the additional parameters within layers II/III and IV, so this included $\mathrm{rl} \rightarrow \mathrm{ss}$, ss $\rightarrow \mathrm{sp}$, ss $\rightarrow \mathrm{si}$, si $\rightarrow \mathrm{sp}, \mathrm{si} \rightarrow \mathrm{si}, \mathrm{sp} \rightarrow$ $\mathrm{sp}$, si $\rightarrow \mathrm{ss}, \mathrm{sp} \rightarrow \mathrm{ss}, \mathrm{dp} \rightarrow \mathrm{tp}, \mathrm{tp} \rightarrow \mathrm{rl}$, and meant the rest of the parameters were fixed (dotted lines in Figure $2 \mathrm{~B}$ ). As we hypothesised that there would be specific effects on AMPA, and potentially NMDA, the decay rates of these channels were also allowed to vary in the model; $G A B A_{A}$ and $G A B A_{B}$ decay rates were fixed.

A)

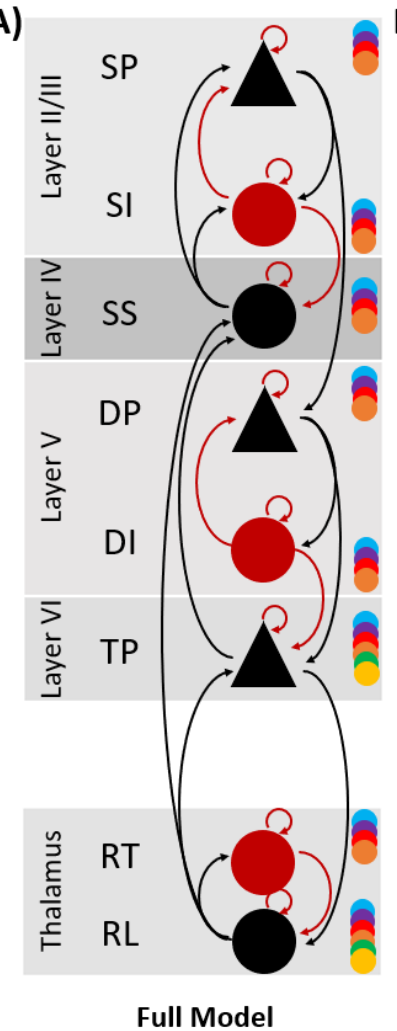

B)



Figure 2. A) Thalamocortical model architecture and connectivity with 6 cell populations in the cortical column, and 2 thalamic populations. Cortical populations include layer II/II with superficial pyramidal (sp), and superficial inhibitory interneuron input (si). Layer IV, the granular layer, has spiny stellate input, and is also the source of thalamic relay input as well as sp input. Layer $V$ is populated by deep pyramidal (DP), and deep inhibitory interneuron input (DP). Layer VI is populated with the thalamic projection (TP) cells, the source of relay input also. The model is also furnished with the decay constant of AMPA, NMDA, GABA-A, GABA-B, and $M$ - and $H$ channels. B) The parameters depicted in terms of whether their priors were fixed or allowed to vary for model inversion. Parameters that were allowed to vary included those outlined by Douglas and Martin (1991) as being key for visual information processing, and the corresponding within-layer connections in II/III and IV C) Key for $A$ and $B$.

The generative model described above was fit to the empirical EEG data using DCM. Since DCM permits simultaneous inversion of multiple experimental conditions, by incorporating a parameterised general-linear model (GLM) into the inversion protocol, we compared three plausible models. First, LTP was modelled as a linear change from baseline that is greatest in the late-post tetanus block [-1 0 1], to reflect early phase LTP and the typical time course of P2 potentiation (Sumner et al., Under 
Review) (Figure 3). As the first measure of potentiation takes place 2 minutes post-tetanus it would be expected that there would be contamination of STP in the first post-tetanus block but not the second. It has been reported that this may explain why potentiation of the $\mathrm{N} 1$ begins to degrade by the late post-tetanus block (Sumner et al., 2020; Sumner et al., Under Review). For this, a non-linear change from baseline, that peaks in the first post-tetanus block (to model contamination with STP),

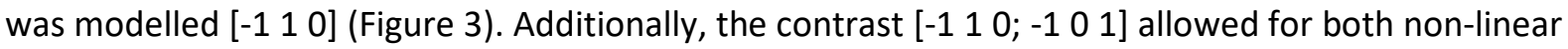
and linear contributions to describe the condition specific effects (Figure 3 ). The winning model was determined using fixed-effects (FFX) Bayesian Model Selection (BMS). FFX was determined to be appropriate given that the biological underpinning of LTP can be assumed to be the same for all healthy humans (Stephan et al., 2010). Following FFX-BMS, a RM-MANOVA that analysed the effect of condition (pre-tetanus, early post-tetanus, and late post-tetanus) on the change in interpopulation synaptic coupling, and time constants was conducted for the linear and non-linear models. Univariate ANOVAs were used to determine the parameters that contributed to a significant effect of condition; corrected for multiple comparisons using false discovery rate (FDR) (Benjamini \& Hochberg, 1995).
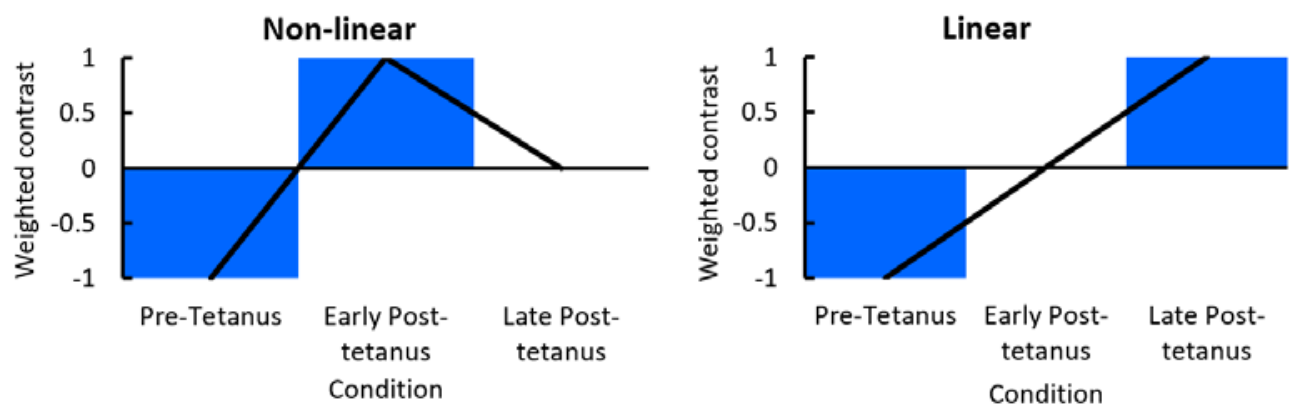

Figure 3. Contrast designs for the non-linear [ $\left[\begin{array}{lll}-1 & 1 & 0\end{array}\right]$ and linear [ $\left[\begin{array}{lll}-1 & 0 & 1\end{array}\right]$ models, where the combination is modelled as having a non-linear and linear contribution [-1 $110 ;-1001]$.

\section{Results}

\section{ERP: Analysis}

The purpose of the ERP analysis was to confirm that the photic tetanus had induced classic modulation of the visually evoked potential. There was a significant effect of photic tetanus on both post-tetanus blocks (using the $F$ contrast [ $1-1-1])$ including a central peak at $224 \mathrm{~ms}\left(\mathrm{~F}_{(1,57)}=136.34, p=7.58 \mathrm{e}^{-13}\right)$ and central $\left(F_{(1,57)}=132.92, p=1.22 \mathrm{e}^{-12}\right)$ and right lateralised $\left(F_{(1,57)}=128.27, p=2.36 \mathrm{e}^{-12}\right)$ significant peaks at $196 \mathrm{~ms}$ within the same cluster. An early centralised peak was also significant at $80 \mathrm{~ms}\left(\mathrm{~F}_{(1,57)}\right.$ $\left.=41.30, p=4.45 \mathrm{e}^{-5}\right)$, with a significant right lateralised peak at $128 \mathrm{~ms}\left(\mathrm{~F}_{(1,57)}=29.29, p=0.0013\right)$, and a $132 \mathrm{~ms}\left(\mathrm{~F}_{(1,57)}=27.34, p=0.0023\right)$ peak in the cluster. Finally an additional early central peak also occurred at $76 \mathrm{~ms}\left(\mathrm{~F}_{(1,57)}=21.20, p=0.015\right)$. Despite the relatively conservative nature of FWE-c, a significant peak also occurred at $8 \mathrm{~ms}\left(F_{(1,57)}=34.74, p=0.0003\right)$, as it is too early to represent visual processing, it likely represents noise.

The post-hoc contrast using the $t$-contrast [ $1-1-1]$ revealed that the evoked response was significantly more negative in the peaks at $80\left(t_{(57)}=6.43, p=2.22 \mathrm{e}^{-5}\right), 128\left(\mathrm{t}_{(57)}=5.41, p=0.001\right)$ and $132 \mathrm{~ms}\left(\mathrm{t}_{(57)}\right.$ $=5.41, p=0.001)$. These findings are consistent with changes to the N1 component. Using the $t-$ contrast [ $\left[\begin{array}{lll}-1 & 1 & 1\end{array}\right]$ the evoked response was more positive in the peaks at $224\left(t_{(57)}=11.68, p<6.12 \mathrm{e}^{-}\right.$ 
bioRxiv preprint doi: https://doi.org/10.1101/2020.02.08.940155; this version posted February 10, 2020. The copyright holder for this preprint (which was not certified by peer review) is the author/funder, who has granted bioRxiv a license to display the preprint in perpetuity. It is made available under aCC-BY-NC-ND 4.0 International license.

$\left.{ }^{13}\right), 196 \mathrm{~ms}\left(\mathrm{t}_{(57)}=11.53, p<6.12 \mathrm{e}^{-13}\right) ;\left(\mathrm{t}_{(57)}=11.33, p<1.18 \mathrm{e}^{-12}\right)$ and $76 \mathrm{~ms}\left(\mathrm{t}_{(57)}=4.60, p=0.008\right)$. The 196 to 224 ms peaks appear to represent and the $P 2$ component becoming more positive, and at 76 may reflect the $\mathrm{P} 1$ becoming more positive. The $\mathrm{P} 2$ increase in the post-tetanus block is illustrated in Figure 4, and also appears to capture a significant decrease in amplitude around the 128-132 ms.

Exploring the early and late post-tetanus conditions separately, the $t$-contrasts [ $1-10$ ] showed the significant peak at $132 \mathrm{~ms}$ reported above $\left(\mathrm{t}_{(57)}=3.99, p=0.043\right)$ and $[-101]$ showed the significant peak at $192 \mathrm{~ms}\left(\mathrm{t}_{(57)}=4.31, p=0.018\right)$, consistent with the tendency for the $\mathrm{N} 1$ to be most significant in the early post-tetanus block, and the P2 in the late (Sumner et al., Under Review). The alternate direction contrasts for each condition had no significant peaks. The early effects are evident on the leading edge of the P2 at POz, in addition to the late effect on the peak of the P2 (Figure 4).

A Evoked response (EEG channel POz) B
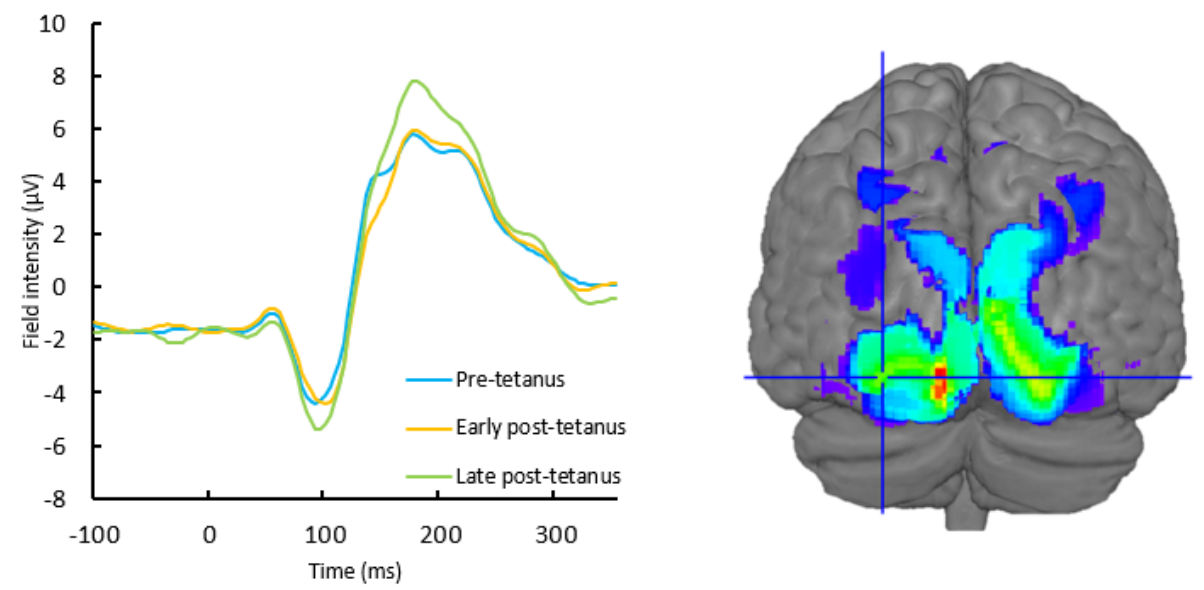

C

Source reconstructed evoked

D

Modelled evoked response
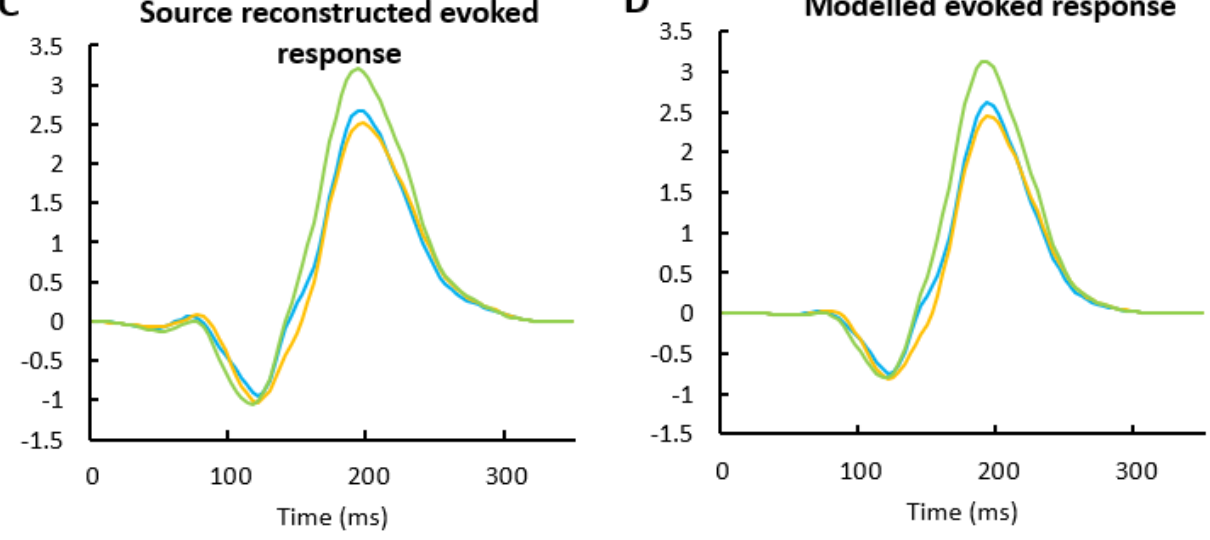

Figure 4. A) The VEP as recorded at electrode POz shows evidence of the differences pre-tetanus compared to both early posttetanus and late post-tetanus found in the peak field effects. This includes a peak at $132 \mathrm{~ms}$ that was most significant in the early post-tetanus block, and at around $196 \mathrm{~ms}$ a peak that was most significant in the late post-tetanus block. B) Results of the source analysis looking at pre-vs early and late post-tetanus. Thresholded to $p<0.05$ uncorrected for illustration purposes. The crosshair lies over the literature selected peak coordinate [-36. -90, 4] in left middle occipital gyrus. C) The time related effects post-tetanus are clearly recapitulated in both the source reconstructed evoked response, D) as well as the evoked response produced at the source by the model. 


\section{Modelling: Analysis}

Source analysis revealed a significant effect of photic tetanus that was particularly strong in visual cortex. As the main peaks were in calcarine fissure and yet the effect of visual LTP has been most typically studied in extrastriate cortex (Clapp et al., 2005; Spriggs et al., 2018; Sumner, Spriggs, et al., 2018a; Sumner et al., 2020; Teyler et al., 2005), a peak in left middle occipital gyrus (MOG) was selected from the literature (Spriggs et al., 2018) that was still within the significant area of activation for the current study: MNI [-36, -90, 4].

FFX revealed that the combinational linear-nonlinear model was the winning computational model ( Figure 5). The individual data fits explained $>80 \%$ variance for all participants for all models. The modelled response in Figure 4 clearly recapitulates the condition effects seen in both the surface recorded ERP at electrode $\mathrm{POz}$ and the source reconstructed response.

Because we were interested in establishing the parameters that contributed to the short-term and long-term potentiation, and the individual fits for all models were good, we extracted the values for the non-linear and linear models separately.

The RM-MANOVA for the effect of condition (pre-tetanus, early post-tetanus, and late post-tetanus) on the interpopulation synaptic coupling, and time constants that was conducted for the non-linear model revealed a significant effect of condition $\left(F_{(24,54)}=7.045, p=1.514 \mathrm{e}^{-9}\right)$ using Wilk's lambda $\lambda=0.059$ (Figure 6). The univariate ANVOA results (Figure 6) revealed that this was driven by a significant increase in conductance in the connection $s s \rightarrow s p\left(F_{(2,54)}=22.36, p=4.203 \mathrm{e}^{-6} \mathrm{FDR}\right)$, and approaching significant increase in $s s \rightarrow$ si $\left(F_{(2,54)}=4.429, p=0.057 \mathrm{FDR}\right.$, or 0.019 uncorrected). There was a significant decrease in $\mathrm{sp} \rightarrow \mathrm{dp}\left(F_{(2,54)}=14.641, p=0.0001 \mathrm{FDR}\right)$. The time constant for AMPA was significantly increased $\left(F_{(2,54)}=11.139, p=0.0006\right.$ FDR $)$.

The RM-MANOVA for the linear model revealed a significant effect of condition $\left(F_{(24,54)}=6.404\right.$, $p=8.120 \mathrm{e}^{-9}$ ) using Wilk's lambda $\lambda=0.068$ (Figure 6). The univariate ANOVA results (Figure 6) revealed a significant increase in $s s \rightarrow s p\left(F_{(2,54)}=6.079, p=0.015 \mathrm{FDR}\right), \mathrm{sp} \rightarrow \mathrm{sp}\left(F_{(2,54)}=6.536, p=0.015 \mathrm{FDR}\right)$, si $\rightarrow \mathrm{ss}$ $\left(F_{(2,54)}=18.902, p=0.000002 \mathrm{FDR}\right)$, and $\mathrm{rl} \rightarrow \mathrm{ss}\left(F_{(2,54)}=13.573, p=0.002 \mathrm{FDR}\right)$.
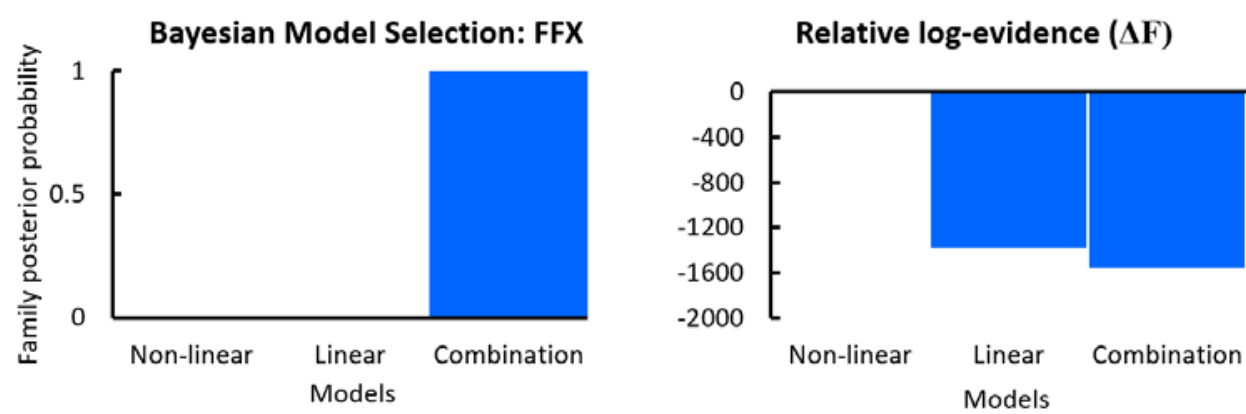

Figure 5. Results of the BMS using FFX demonstrating that a combination of both linear and non-linear effects best describe the data. The next best model represented a difference in log-evidence ( $\triangle F)$ between the two highest scoring models of 1382.86 for the linear model, and 1554.79 for the combination model, relative to the non-linear model alone. This indicates $>99 \%$ posterior confidence in the winning model. 


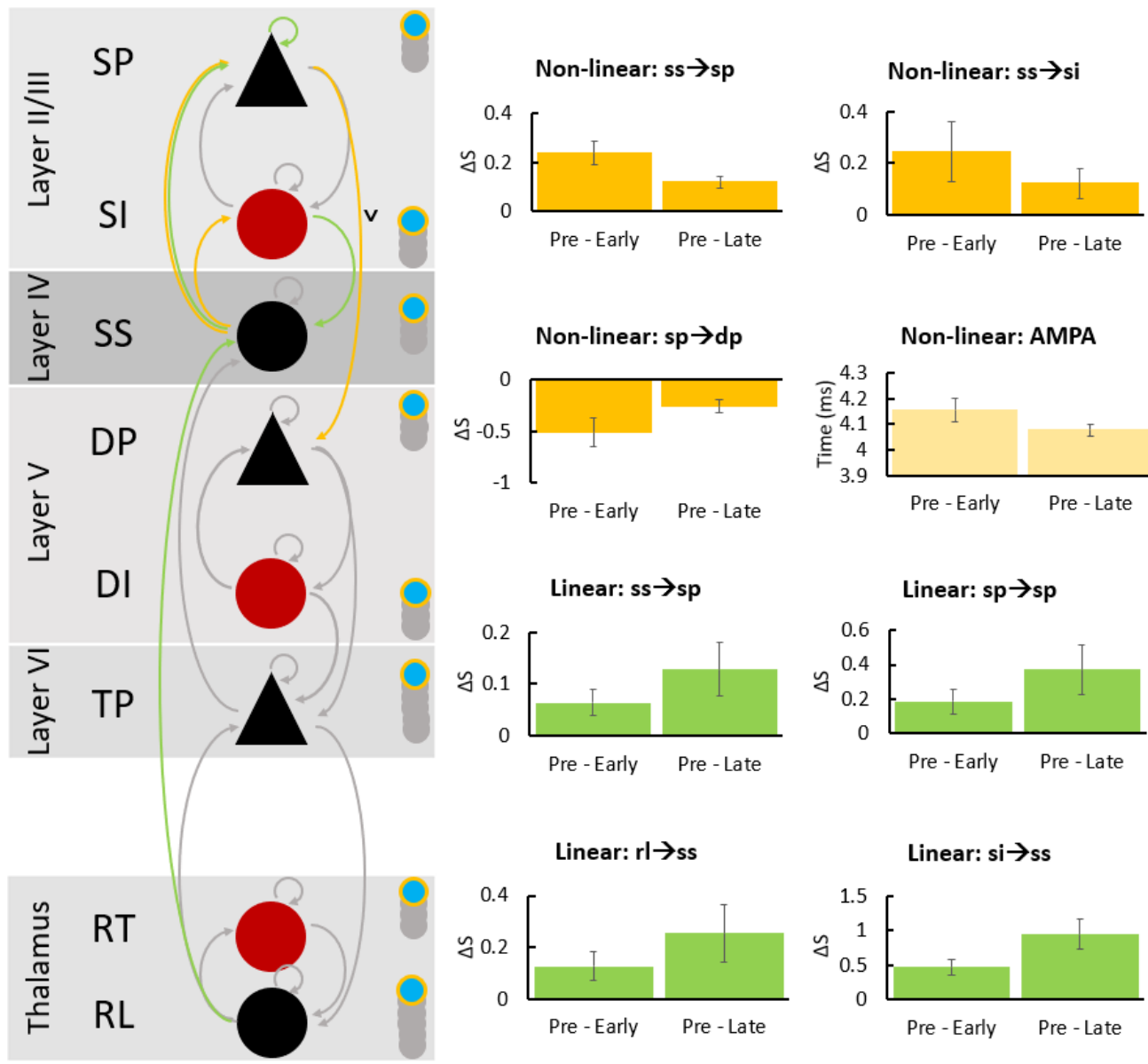

Figure 6. The RM-MANOVA on the task-specific effects for both the non-linear (yellow) and linear (green) models demonstrated that the connectivity between spiny stellates (ss) and superficial pyramidal cells (sp) were greater than pretetanus in both the early and late post-tetanus conditions. Non-linear task-specific effects included significant changes in ss to superficial inhibitory interneuron (si) connectivity, and $s p$ to deep pyramidal (dp) connectivity. For $s p$ to $d p$ this was a decrease in connectivity (connection indicated by $a \vee$ ). The AMPA decay constant was significantly longer than pre-tetanus for both conditions post-tetanus, but degraded by late post-tetanus. For linear effects, the self-gain of sp was significant, as was si to ss. Thalamic relay to ss was also significant.

\section{Discussion}

The current study set out to validate a thalamocortical model of the microcircuit structure of visual cortex for exploring event related potential data, in particular to explore its utility in the non-invasive visually induced LTP paradigm. It was hypothesised that the model would be able to reproduce connectivity changes found in invasive animal research, providing an in vivo method for measuring changes to the laminar connectivity in visual cortex induced by LTP. The use of non-linear and linear contrasts was set up to capture the STP as well as the E-LTP driven parameter changes. The combination of both was found to best describe the data, providing validation for the idea that the trial specific changes seen in the ERPs contain both STP and E-LTP effects on the underlying cortical microcircuitry (Sumner et al., 2020; Sumner et al., Under Review). The visual LTP paradigm was found to induce both linear and non-linear changes to the excitatory connection from ss to sp, indicating the contribution of both STP and LTP mechanisms. A linear increase in rl (thalamic) to ss (layer IV) excitatory connectivity also indicated LTP related increases had occurred. Both changes had been demonstrated by Heynen and Bear (2001) following photic and TBS induction protocols; ss (layer IV) to sp (layer II/III) has also been shown in primates by Huang et al. (2014), thus providing validation for 
bioRxiv preprint doi: https://doi.org/10.1101/2020.02.08.940155; this version posted February 10, 2020. The copyright holder for this preprint (which was not certified by peer review) is the author/funder, who has granted bioRxiv a license to display the preprint in perpetuity. It is made available under aCC-BY-NC-ND 4.0 International license.

the use of this model and confirming our hypotheses. Additional changes were found, potentially due to the nature of the larger field recorded from the scalp with EEG compared to layer specific implanted electrodes. The changes included ss $\rightarrow \mathrm{si}$, and si $\rightarrow$ si reciprocal connectivity, sp self-gain, and a decrease in the $\mathrm{sp} \rightarrow \mathrm{dp}$ connectivity. The decay constant of AMPA was also increased from pretetanus. Overall the study provides remarkably plausible changes to the microcircuit following visually induced LTP.

The visual LTP paradigm benefits from the fact that the visual cortex is a primary site of LTP research in neocortex. This led to the ability to make strong hypotheses in the current study of how the thalamocortical model would recapitulate the effects of photic tetanus in laminar connectivity changes. As briefly introduced above, Heynen and Bear (2001) have demonstrated that potentiation leads to excitatory feed forward connectivity into layer IV rising from modification of the thalamocortical projection, evidenced also in the modification of field potentials (Heynen \& Bear, 2001). They also showed contemporaneous increases in superficial layer II/III current sinks. This was established as being a separate site of LTP (Heynen \& Bear, 2001); further supported by Huang et al. (2014) who demonstrated inducing LTP at layer IV potentiated field potentials at layer III. Replicating these connectivity changes in the current study provided the primary evidence that the model was producing plausible changes, consistent with invasive animal LTP research. The effects on the model also provide validation that the visual LTP paradigm is producing changes to laminar connectivity consistent with LTP driven effects, as well as modulation of VEPs post-photic tetanus. Further, the replication of changes seen in electrical induction protocols indicates that the photic tetanus is activating neural circuitry in a manner similar to electrical tetanic bursts as hypothesised in Clapp et al. (2012).

In addition to the changes to thalamocortical connectivity reported above, further changes found may reveal additional insight into the effect of the photic tetanus on laminar connectivity, though these findings are relatively more exploratory. There was a significant non-linear decrease in the excitatory connection from sp (layer II/III) $\rightarrow$ dp (layer V) that may be explainable by LTD. LTD is as important to learning and memory as LTP (Bliss \& Cooke, 2011). Homosynaptic LTD is a long-term decrease or weakening of synaptic efficacy (Bliss \& Cooke, 2011). In contrast to LTP, LTD is induced by slow $\sim 1-3 \mathrm{~Hz}$ stimulation (Bear \& Abraham, 1996; Dudek \& Bear, 1992; Kemp \& Manahan-Vaughan, 2004). It has previously been speculated that the $\sim 1 \mathrm{~Hz}$ or slow stimulation in the visual LTP paradigm may induce homosynaptic LTD related changes to the VEP, in addition to LTP from the photic-tetanus (Jahshan, Wynn, Mathalon, \& Green, 2017; Normann, Schmitz, Furmaier, Doing, \& Bach, 2007; Spriggs et al., 2017). However, the non-linear change in the connection from $s p$ to $d p$ indicates the contribution of a shorter-term depression that does not return fully to baseline by the late post-tetanus block. This may be consistent with reports by Forsyth et al. (2015) on heterosynaptic LTD occurring with the visual LTP paradigm. The limited research on heterosynaptic LTD in neocortex demonstrates relatively greater transience ( $\sim 10 \mathrm{~min}$ ) than homosynaptic LTP and LTD (Castro-Alamancos, Donoghue, \& Connors, 1995). Heterosynaptic LTD provides a number of important mechanisms for maintaining stable neuronal networks, by preventing runaway dynamics inherent in a purely Hebbian plasticity system governed by homosynaptic processes (Chistiakova, Bannon, Bazhenov, \& Volgushev, 2014)).

While a transient activation of NMDARs initiate LTP, it is expressed as a persistent increase in AMPAR transmission (Benke, Lüthi, Isaac, \& Collingridge, 1998). Relatively greater changes to AMPARs including the phosphorylation and trafficking of new receptors occur in the first 40 minutes which have been shown to change AMPAR time dynamics and opening probability (Banke et al., 2000; Benke et al., 1998; Nayak, Zastrow, Lickteig, Zahniser, \& Browning, 1998; Watt, Sjöström, Häusser, Nelson, \& Turrigiano, 2004; Williams et al., 2007), the AMPAR numbers begin to decline by 4 hours (Watt et al., 
2004; Williams et al., 2007). While changes to the decay constant for AMPARs or NMDARs has not typically been found in invasive research, when measured as pooled changes the increase in variance cause by the relatively larger number of receptors and higher opening probability may plausibly lead to increases in the mean decay constant, as found in the current study. There is a slower increase in the trafficking of NMDARs, that restores the ratio of AMPAR to NMDAR signalling within 2 hours (Williams et al., 2007), and may be why this effect was only seen in the AMPAR time constant and not NMDAR. The thalamocortical model does not calculate single channel conductance that would have better allowed for quantification of the change in AMPARs.

The role of inhibitory interneurons in Hebbian long-term potentiation is less well established. However, LTP on inhibitory interneurons has been demonstrated in both visual cortex and hippocampus (Kullmann \& Lamsa, 2011; Sarihi et al., 2008), it may not always be Hebbian, and it may or may not be NMDAR dependent. The finding of increased inhibitory input into ss, with the reciprocal but shorter-term increase in ss to si input is a plausible and interesting interaction of LTP. In rodents, layer IV somatosensory cortex has shown that thalamocortical input mediates LTP in inhibitory interneurons (Chittajallu \& Isaac, 2010). Feed-forward inhibition into layer IV truncates LTP in ss cells and is essential for specific, coordinated, and healthy sensory processing (Chittajallu \& Isaac, 2010). It is not clear whether the change observed in the current study is NMDA dependent and provides an interesting area for future exploration in clinical and pharmacological research.

The changes to the visual laminar connectivity in the thalamocortical model following visually induced LTP demonstrated remarkable consistency with the results of rodent invasive research. In particular the increase in conductance in the excitatory connection from the thalamic relay pathway to layer IV, and from layer IV to layer II/III, established major sites of LTP in visual (Heynen \& Bear, 2001; Huang et al., 2014; Kirkwood, Rioult, \& Bear, 1996). Additional changes include LTP at inhibitory interneurons and the possibility of LTD decreasing excitation in the projection from superficial sp into $\mathrm{dp}$. These findings provide justification for the implementation of the presented thalamocortical model for ERP research in order to provide increased detail on the nature of changes that underlie LTP induced in visual cortex, and for translating rodent finding of the deficits to LTP that may underlie neurological and psychiatric disease to non-invasive research in humans.

Conflicts of interest: None to declare.

Acknowledgements: We would like to thank lan Kirk and Suresh Muthukumaraswamy for the use of data. MS was supported by Brain Research New Zealand. ADS is supported by a Wellcome Strategic Award (104943/Z/14/Z). 
bioRxiv preprint doi: https://doi.org/10.1101/2020.02.08.940155; this version posted February $10,2020$. The copyright holder for this preprint (which was not certified by peer review) is the author/funder, who has granted bioRxiv a license to display the preprint in perpetuity. It is made available under aCC-BY-NC-ND 4.0 International license.

\section{References:}

Adams, N. E., Hughes, L. E., Phillips, H. N., Shaw, A. D., Murley, A. G., Nesbitt, D., . . Rowe, J. B. (2020). GABA-ergic dynamics in human frontotemporal networks confirmed by pharmacomagnetoencephalography. Journal of Neuroscience

Banke, T. G., Bowie, D., Lee, H.-K., Huganir, R. L., Schousboe, A., \& Traynelis, S. F. (2000). Control of GluR1 AMPA Receptor Function by CAMP-Dependent Protein Kinase. The Journal of Neuroscience, 20(1), 89-102. 10.1523/jneurosci.20-01-00089.2000

Bastos, A. M., Usrey, W. M., Adams, R. A., Mangun, G. R., Fries, P., \& Friston, K. J. (2012). Canonical microcircuits for predictive coding. Neuron, 76(4), 695-711.

Bear, M. F., \& Abraham, W. C. (1996). Long-term depression in hippocampus. Annual review of neuroscience, 19(1), 437-462.

Benjamini, Y., \& Hochberg, Y. (1995). Controlling the false discovery rate: a practical and powerful approach to multiple testing. Journal of the royal statistical society. Series $B$ (Methodological), 289-300.

Benke, T. A., Lüthi, A., Isaac, J. T. R., \& Collingridge, G. L. (1998). Modulation of AMPA receptor unitary conductance by synaptic activity. Nature, 393(6687), 793-797. 10.1038/31709

Bliss, T. V. P., \& Collingridge, G. L. (1993). A synaptic model of memory: long-term potentiation in the hippocampus. Nature, 361(6407), 31-39.

Bliss, T. V. P., \& Cooke, S. F. (2011). Long-term potentiation and long-term depression: a clinical perspective. Clinics, 66, 3-17.

Bliss, T. V. P., \& Lømo, T. (1973). Long-lasting potentiation of synaptic transmission in the dentate area of the anaesthetized rabbit following stimulation of the perforant path. The Journal of Physiology, 232(2), 331-356. 10.1113/jphysiol.1973.sp010273

Brainard, D. H. (1997). The psychophysics toolbox. Spatial vision, 10, 433-436.

Castro-Alamancos, M. A., Donoghue, J. P., \& Connors, B. W. (1995). Different forms of synaptic plasticity in somatosensory and motor areas of the neocortex. Journal of Neuroscience, 15(7), 5324-5333.

Chistiakova, M., Bannon, N. M., Bazhenov, M., \& Volgushev, M. (2014). Heterosynaptic plasticity: multiple mechanisms and multiple roles. The Neuroscientist, 20(5), 483-498.

Chittajallu, R., \& Isaac, J. T. (2010). Emergence of cortical inhibition by coordinated sensory-driven plasticity at distinct synaptic loci. Nat Neurosci, 13(10), 1240.

Clapp, W. C., Eckert, M. J., Teyler, T. J., \& Abraham, W. C. (2006). Rapid visual stimulation induces Nmethyl-D-aspartate receptor-dependent sensory long-term potentiation in the rat cortex. NeuroReport, 17(5), 511-515. 10.1097/01.wnr.0000209004.63352.10

Clapp, W. C., Hamm, J. P., Kirk, I. J., \& Teyler, T. J. (2012). Translating long-term potentiation from animals to humans: a novel method for noninvasive assessment of cortical plasticity. Biol Psychiatry, 71(6), 496-502. 10.1016/j.biopsych.2011.08.021

Clapp, W. C., Zaehle, T., Lutz, K., Marcar, V. L., Kirk, I. J., Hamm, J. P., . . Jancke, L. (2005). Effects of long-term potentiation in the human visual cortex: a functional magnetic resonance imaging study. NeuroReport, 16(18), 1977-1980.

Cooke, S. F., \& Bear, M. F. (2010). Visual experience induces long-term potentiation in the primary visual cortex. The Journal of Neuroscience, 30(48), 16304-16313. 10.1523/JNEUROSCI.433310.2010

Douglas, R. J., \& Martin, K. (1991). A functional microcircuit for cat visual cortex. The Journal of Physiology, 440(1), 735-769.

Douglas, R. J., \& Martin, K. A. (2004). Neuronal circuits of the neocortex. Annu. Rev. Neurosci., 27, 419451.

Douglas, R. J., Martin, K. A., \& Whitteridge, D. (1989). A canonical microcircuit for neocortex. Neural Computation, 1(4), 480-488. 
bioRxiv preprint doi: https://doi.org/10.1101/2020.02.08.940155; this version posted February 10, 2020. The copyright holder for this preprint (which was not certified by peer review) is the author/funder, who has granted bioRxiv a license to display the preprint in perpetuity. It is made available under aCC-BY-NC-ND 4.0 International license.

Dudek, S., \& Bear, M. F. (1992). Homosynaptic long-term depression in area CA1 of hippocampus and effects of <inline-formula $>\mathrm{N}<$ /inline-formula $>$-methyl-D-aspartate receptor blockade How We Learn; How We Remember: Toward an Understanding of Brain and Neural Systems (pp. 200-204).

Eckert, M. J., Guevremont, D., Williams, J. M., \& Abraham, W. C. (2013). Rapid visual stimulation increases extrasynaptic glutamate receptor expression but not visual-evoked potentials in the adult rat primary visual cortex. Eur J Neurosci, 37(3), 400-406. 10.1111/ejn.12053

Felleman, D. J., \& Van Essen, D. C. (1991). Distributed hierarchical processing in the primate cerebral cortex. Cereb Cortex, 1(1), 1-47.

Forsyth, J. K., Bachman, P., Mathalon, D. H., Roach, B. J., \& Asarnow, R. F. (2015). Augmenting NMDA receptor signaling boosts experience-dependent neuroplasticity in the adult human brain. Proceedings of the National Academy of Sciences, 112(50), 15331-15336. 10.1073/pnas.1509262112

Heynen, A. J., \& Bear, M. F. (2001). Long-term potentiation of thalamocortical transmission in the adult visual cortex in vivo. The Journal of Neuroscience, 21(24), 9801-9813.

Huang, S., Rozas, C., Treviño, M., Contreras, J., Yang, S., Song, L., . . Kirkwood, A. (2014). Associative Hebbian Synaptic Plasticity in Primate Visual Cortex. The Journal of Neuroscience, 34(22), 7575-7579. 10.1523/jneurosci.0983-14.2014

Jahshan, C., Wynn, J. K., Mathalon, D. H., \& Green, M. F. (2017). Cognitive correlates of visual neural plasticity in schizophrenia. Schizophrenia Research, 190, 39-45. https://doi.org/10.1016/j.schres.2017.03.016

Jansen, B. H., \& Rit, V. G. (1995). Electroencephalogram and visual evoked potential generation in a mathematical model of coupled cortical columns. Biological Cybernetics, 73(4), 357-366. 10.1007/bf00199471

Kemp, A., \& Manahan-Vaughan, D. (2004). Hippocampal long-term depression and long-term potentiation encode different aspects of novelty acquisition. Proceedings of the National Academy of Sciences, 101(21), 8192-8197.

Kilner, J. M., \& Friston, K. J. (2010). Topological inference for EEG and MEG. The Annals of Applied Statistics, 1272-1290.

Kirk, I. J., McNair, N. A., Hamm, J. P., Clapp, W. C., Mathalon, D. H., Cavus, I., \& Teyler, T. J. (2010). Long-term potentiation (LTP) of human sensory-evoked potentials. Wiley Interdisciplinary Reviews: Cognitive Science, 1(5), 766-773. 10.1002/wcs.62

Kirkwood, A., \& Bear, M. F. (1994). Hebbian synapses in visual cortex. Journal of Neuroscience, 14(3), 1634-1645.

Kirkwood, A., Rioult, M. G., \& Bear, M. F. (1996). Experience-dependent modification of synaptic plasticity in visual cortex. Nature, 381(6582), 526-528.

Kleiner, M., Brainard, D., Pelli, D., Ingling, A., Murray, R., \& Broussard, C. (2007). What's new in Psychtoolbox-3. Perception, 36(14), 1.

Kullmann, D. M., \& Lamsa, K. P. (2011). LTP and LTD in cortical GABAergic interneurons: Emerging rules $\begin{array}{llll}\text { and } & \text { roles. }\end{array}$ https://doi.org/10.1016/i.neuropharm.2010.12.020

Litvak, V., \& Friston, K. (2008). Electromagnetic source reconstruction for group studies. Neuroimage, 42(4), 1490-1498. https://doi.org/10.1016/j.neuroimage.2008.06.022

Lumer, E. D., Edelman, G. M., \& Tononi, G. (1997). Neural dynamics in a model of the thalamocortical system. I. Layers, loops and the emergence of fast synchronous rhythms. Cerebral cortex (New York, NY: 1991), 7(3), 207-227.

Malenka, R. C. (1991). Postsynaptic factors control the duration of synaptic enhancement in area CA1 of the hippocampus. Neuron, 6(1), 53-60. http://dx.doi.org/10.1016/0896-6273(91)90121-F

McNair, N. A., Clapp, W. C., Hamm, J. P., Teyler, T. J., Corballis, M. C., \& Kirk, I. J. (2006). Spatial frequency-specific potentiation of human visual-evoked potentials. NeuroReport, 17(7), 739741. 10.1097/01.wnr.0000215775.53732.9f 
bioRxiv preprint doi: https://doi.org/10.1101/2020.02.08.940155; this version posted February 10, 2020. The copyright holder for this preprint (which was not certified by peer review) is the author/funder, who has granted bioRxiv a license to display the preprint in perpetuity. It is made available under aCC-BY-NC-ND 4.0 International license.

Moran, R. J., Jones, M. W., Blockeel, A. J., Adams, R. A., Stephan, K. E., \& Friston, K. J. (2015). Losing control under ketamine: suppressed cortico-hippocampal drive following acute ketamine in rats. Neuropsychopharmacology, 40(2), 268-277. 10.1038/npp.2014.184

Moran, R. J., Pinotsis, D. A., \& Friston, K. (2013). Neural masses and fields in dynamic causal modeling. Frontiers in computational neuroscience, 7

Moran, R. J., Symmonds, M., Stephan, K. E., Friston, K. J., \& Dolan, R. J. (2011). An in vivo assay of synaptic function mediating human cognition. Current biology : CB, 21(15), 1320-1325. 10.1016/j.cub.2011.06.053

Morris, C., \& Lecar, H. (1981). Voltage oscillations in the barnacle giant muscle fiber. Biophysical Journal, 35(1), 193-213. https://doi.org/10.1016/S0006-3495(81)84782-0

Murakami, S., \& Okada, Y. (2006). Contributions of principal neocortical neurons to magnetoencephalography and electroencephalography signals. The Journal of Physiology, 575(3), 925-936.

Muthukumaraswamy, S. D., Shaw, A. D., Jackson, L. E., Hall, J., Moran, R., \& Saxena, N. (2015). Evidence that subanesthetic doses of ketamine cause sustained disruptions of NMDA and AMPAmediated frontoparietal connectivity in humans. The Journal of Neuroscience, 35(33), 1169411706.

Nayak, A., Zastrow, D. J., Lickteig, R., Zahniser, N. R., \& Browning, M. D. (1998). Maintenance of latephase LTP is accompanied by PKA-dependent increase in AMPA receptor synthesis. Nature, 394(6694), 680-683. 10.1038/29305

Normann, C., Schmitz, D., Furmaier, A., Doing, C., \& Bach, M. (2007). Long-term plasticity of visually evoked potentials in humans is altered in major depression. Biol Psychiatry, 62(5), 373-380. 10.1016/j.biopsych.2006.10.006

Pelli, D. G. (1997). The VideoToolbox software for visual psychophysics: Transforming numbers into movies. Spatial vision, 10(4), 437-442.

Ross, R. M., McNair, N. A., Fairhall, S. L., Clapp, W. C., Hamm, J. P., Teyler, T. J., \& Kirk, I. J. (2008). Induction of orientation-specific LTP-like changes in human visual evoked potentials by rapid sensory stimulation. Brain Res Bull, 76(1-2), 97-101. 10.1016/j.brainresbull.2008.01.021

Sarihi, A., Jiang, B., Komaki, A., Sohya, K., Yanagawa, Y., \& Tsumoto, T. (2008). Metabotropic Glutamate Receptor Type 5-Dependent Long-Term Potentiation of Excitatory Synapses on Fast-Spiking GABAergic Neurons in Mouse Visual Cortex. The Journal of Neuroscience, 28(5), 1224-1235. 10.1523/jneurosci.4928-07.2008

Shaw, A. D., Muthukumaraswamy, S. D., Saxena, N., Adams, N., Moran, R. J., \& Singh, K. D. (2019). Insilico evidence that increased cortico-thalamic connectivity and superficial pyramidal disinhibition underlie broadband task-related spectral changes induced by ketamine. bioRxiv, 688044.

Skrandies, W. (1985). Critical flicker fusion and double flash discrimination in different parts of the visual field. International journal of neuroscience, 25(3-4), 225-231.

Smith, C., \& McMahon, L. L. (2005). Estrogen-Induced Increase in the Magnitude of Long-Term Potentiation Occurs Only When the Ratio of NMDA Transmission to AMPA Transmission Is Increased. The Journal of Neuroscience, 25(34), 7780-7791. 10.1523/jneurosci.0762-05.2005

Spriggs, M. J., Cadwallader, C. J., Hamm, J. P., Tippett, L. J., \& Kirk, I. J. (2017). Age-related alterations in human neocortical plasticity. Brain Res Bull, 130, 53-59. http://dx.doi.org/10.1016/j.brainresbull.2016.12.015

Spriggs, M. J., Sumner, R. L., McMillan, R. L., Moran, R. J., Kirk, I. J., \& Muthukumaraswamy, S. D. (2018). Indexing sensory plasticity: Evidence for distinct Predictive Coding and Hebbian learning mechanisms in the cerebral cortex. Neuroimage, 176, 290-300. https://doi.org/10.1016/j.neuroimage.2018.04.060

Stephan, K. E., Penny, W. D., Moran, R. J., den Ouden, H. E. M., Daunizeau, J., \& Friston, K. J. (2010). Ten simple rules for dynamic causal modeling. Neuroimage, 49(4), 3099-3109. http://dx.doi.org/10.1016/j.neuroimage.2009.11.015 
Sumner, R., Spriggs, M., McMillan, R., Sundram, F., Kirk, I., \& Muthukumaraswamy, S. (2018a). Neural plasticity is modified over the human menstrual cycle: combined insight from sensory evoked potential LTP and repetition suppression. Neurobiology of learning and memory, 155, 422434.

Sumner, R. L., McMillan, R., Spriggs, M. J., Campbell, D., Malpas, G., Maxwell, E., . . . Muthukumaraswamy, S. D. (2020). Ketamine Enhances Visual Sensory Evoked Potential Longterm Potentiation in Patients With Major Depressive Disorder. Biol Psychiatry Cogn Neurosci Neuroimaging, 5(1), 45-55. 10.1016/j.bpsc.2019.07.002

Sumner, R. L., McMilllan, R. L., Shaw, A. D., Singh, K. D., Sundram, F., \& Muthukumaraswamy, S. D. (2018). Peak visual gamma frequency is modified across the healthy menstrual cycle. Hum Brain Mapp

Sumner, R. L., Spriggs, M. J., McMillan, R. L., Sundram, F., Kirk, I. J., \& Muthukumaraswamy, S. D. (2018b). Neural plasticity is modified over the human menstrual cycle: Combined insight from sensory evoked potential LTP and repetition suppression. Neurobiology of learning and memory, 155, 422-434. https://doi.org/10.1016/j.nlm.2018.08.016

Sumner, R. L., Spriggs, M. J., Muthukumaraswamy, S. D., \& Kirk, I. J. (Under Review). The role of Hebbian learning in human perception: a methodological and theoretical review of the human Visual Long-Term Potentiation paradigm. Neurosci Biobehav Rev

Teyler, T. J., \& DiScenna, P. (1987). Long-term potentiation. Annual review of neuroscience, 10(1), 131161.

Teyler, T. J., Hamm, J. P., Clapp, W. C., Johnson, B. W., Corballis, M. C., \& Kirk, I. J. (2005). Long-term potentiation of human visual evoked responses. European Journal of Neuroscience, 21(7), 2045-2050. 10.1111/j.1460-9568.2005.04007.x

Warren, S. G., Humphreys, A. G., Juraska, J. M., \& Greenough, W. T. (1995). LTP varies across the estrous cycle: enhanced synaptic plasticity in proestrus rats. Brain Research, 703(1-2), 26-30. http://doi.org/10.1016/0006-8993(95)01059-9

Watt, A. J., Sjöström, P. J., Häusser, M., Nelson, S. B., \& Turrigiano, G. G. (2004). A proportional but slower NMDA potentiation follows AMPA potentiation in LTP. Nat Neurosci, 7(5), 518-524. $10.1038 / \mathrm{nn} 1220$

Williams, J. M., Guévremont, D., Mason-Parker, S. E., Luxmanan, C., Tate, W. P., \& Abraham, W. C. (2007). Differential Trafficking of AMPA and NMDA Receptors during Long-Term Potentiation in Awake Adult Animals. The Journal of Neuroscience, 27(51), 14171. 10.1523/JNEUROSCI.2348-07.2007 